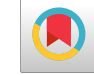

\title{
Acute Respiratory Infection in Co-Infection Form of Bacteria and Virus, Human Bocavirus with Streptococcus pneumoniae: A Case Report
}

\author{
Mehrdad Mohammadi (iB), \\ ${ }^{1}$ Department of Microbiology and Immunology, School of Medicine, Kashan University of Medical Sciences, Kashan, Iran \\ "Corresponding author: Ph.D. student of Medical Bacteriology, Department of Microbiology and Immunology, School of Medicine, Kashan University of Medical Sciences, \\ Kashan, Iran. Email: mehrdad.mohammadi1984@gmail.com
}

Received 2020 June 15; Revised 2020 June 27; Accepted 2020 July 08.

\begin{abstract}
Introduction: Human bocavirus (HBoV) belongs to the Parvoviridae family, which has been revealed to be associated with respiratory and gastrointestinal infections in children. There are many reports worldwide on respiratory infection or gastroenteritis caused by this virus.

Case Presentation: In a twin case (a girl and a boy), we demonstrated that HBoV infection in combination with Streptococcus pneumonia as co-infection caused the death of a 14-month-old girl with a history of high fever and wheezing. A week later, her brother presented with almost the same symptoms, but only $\mathrm{HBoV}$ was found in a nasopharyngeal aspirate sample.

Discussion: This case suggests that lower respiratory tract infections due to HBoV may cause severe and life-threatening diseases, resulting in death in combination with a bacterial infection, such as S. pneumonia. The study suggests replacing multiplex PCR as a fast and meticulous method instead of conventional and time-consuming microbiological methods for determining the causative organism for respiratory infections.
\end{abstract}

Keywords: Human bocavirus, Respiratory Tract Infections, Coinfection, Streptococcus pneumoniae, Multiplex Polymerase Chain Reaction

\section{Introduction}

One of the most common infections worldwide is respiratory tract infection. Pneumonia is a serious cause of mortality and morbidity. It also is the leading infectious disease death in children under five years of age. Most deaths due to pneumonia occur in developing countries. Viral pathogens are the most common etiology of respiratory infections in children, but usually, the exact pathogen cannot be determined $(1,2)$. The human bocavirus ( $\mathrm{HBoV})$ was first identified in 2005 by Allander et al. (3). The virus belongs to the Parvoviridae family and includes four subtypes. HBoV-1 is associated with respiratory disease in children, while HBoV-2, HBoV-3, and HBoV-4 commonly cause gastroenteritis (4-6). HBoV respiratory infection commonly presents as mild or self-limiting disease, and even it may be asymptomatic $(5,7)$. The signs and symptoms of respiratory infection in children include rhinitis, cough, dyspnea, wheezing, fever, and diarrhea (7-9). Multiplex polymerase chain reaction (PCR) is a quick, reliable, and precise method for the evaluation of a wide spectrum of microbial targets. This technique can detect several viruses, bacteria, and fungi in the respiratory sample (10). Here, we describe two children with a severe acute respi- ratory infection (ARI) with $\mathrm{HBoV}$ as the causative agent detected by multiplex PCR. In one of the cases, the patient died of streptococcus pneumonia co-infection with a virus.

\section{Case Presentation}

\subsection{Case 1}

A14-month old girl was admitted to the emergency department of Mofid hospital (Tehran, Iran). She was born premature (gestational age: 34 weeks, birth weight: $2 \mathrm{~kg}$ ) and had a history of hospitalization two times: once in the neonatal period and the other at the age of 6 months, both because of respiratory infection. Two days before referral, she was febrile with coughing and rhinorrhea. Despite using acetaminophen, she had a high-grade fever, poor feeding, and restlessness. Physical examination indicated tachycardia and respiratory distress, including tachypnea and intercostal retraction. On chest examination, bilateral wheezing and fine crackle were heard. Abdomen and limb examinations were normal. Vital Signs were as follows: pulse rate: $144 / \mathrm{min}$, respiratory rate $=76 / \mathrm{min}$, axillary temperature $=38.5^{\circ} \mathrm{C}$ (Table 1$)$.

Chest X-ray illustrated diffuse bilateral patchy infiltration (Figure 1). In the laboratory, serum electrolytes were 


\begin{tabular}{|c|c|c|}
\hline Clinical Examinations Results & First Case (Female) & Second Case (Male) \\
\hline Cough & Present & Present \\
\hline Rhinorrhea & Present & Present \\
\hline Wheezing & Present & Present \\
\hline Fever & $38.5^{\circ} \mathrm{C}$ & 38.8 \\
\hline Tachycardia & Present [pulse rate: $144 / \mathrm{min}$ ] & Present [pulse rate: $130 / \mathrm{min}$ ] \\
\hline Dyspnea & Present & Present \\
\hline Respiratory rate, breaths/min & 76 & 72 \\
\hline Weight, g & 2000 & 2100 \\
\hline Hypoxia & Present [arterial $\mathrm{O}_{2}$ saturation $\left.=80 \%\right]$ & Present $\left[\right.$ arterial $\mathrm{O}_{2}$ saturation $\left.=78 \%\right]$ \\
\hline
\end{tabular}

within normal ranges, and the results of the complete blood count (CBC) test were as follows: hemoglobin: 11.5 g/dL, platelet: $225000 / \mu \mathrm{L}$, and white blood cells: $7200 / \mu \mathrm{L}$ (neutrophil: 60\%, lymphocyte: 40\%). Pulse oximetry showed hypoxia (arterial $\mathrm{O}_{2}$ saturation $=80 \%$ ) $($ Table 1$)$; thus, an $\mathrm{O}_{2}$ face mask ( $5 \mathrm{~L} / \mathrm{min}$ ) was applied for the patient, and Salbutamol was nebulized. Due to progressive respiratory distress, she was transferred to the Pediatric Intensive Care Unit (PICU). Ceftriaxone and clindamycin were initiated after sending a sample for blood culture as a treatment of the pediatric community-acquired pneumonia and staphylococcus aureus infection. Due to the H1N1 influenza outbreak, a nasopharyngeal aspirate sample was sent for viral investigation. Also, oseltamivir was prescribed. On the second day, as a result of respiratory distress exacerbation, the patient was intubated and mechanical ventilation was done. Moreover, antibiotics were changed to vancomycin and meropenem for broadspectrum coverage of Gram-positive and Gram-negative microorganisms. The patient's general condition gradually became worse. Consultation with intensivist was done for ventilator readjustment. Finally, the patient had respiratory and heart failure and expired. THE influenza PCR test result was negative, and the multiplex PCR test result was positive for HBoV and S. pneumoniae. Multiplex PCR was performed on nasopharyngeal aspiration (NPA) sample by FTD Respiratory 21 plus multiplex PCR kit (Fasttrack Diagnostics, Luxemburg). The kit was able to detect important pathogens for respiratory infection, including Chlamydophila pneumonia, Enterovirus, haemophilus influenza B, human adenovirus, human bocavirus, human coronavirus 229E, human coronavirus HUK1, human coronavirus NL63, Human coronavirus OC43, human metapneumoviruses $\mathrm{A} / \mathrm{B}$, human parainfluenza viruses $1,2,3$, and 4 , human parechovirus, human respiratory syncytial viruses $A / B$, human rhinovirus, H1N1 influenza virus (swine-lineage), influenza B virus, Mycoplasma pneumoniae, S. aureus, and S. pneumonia.

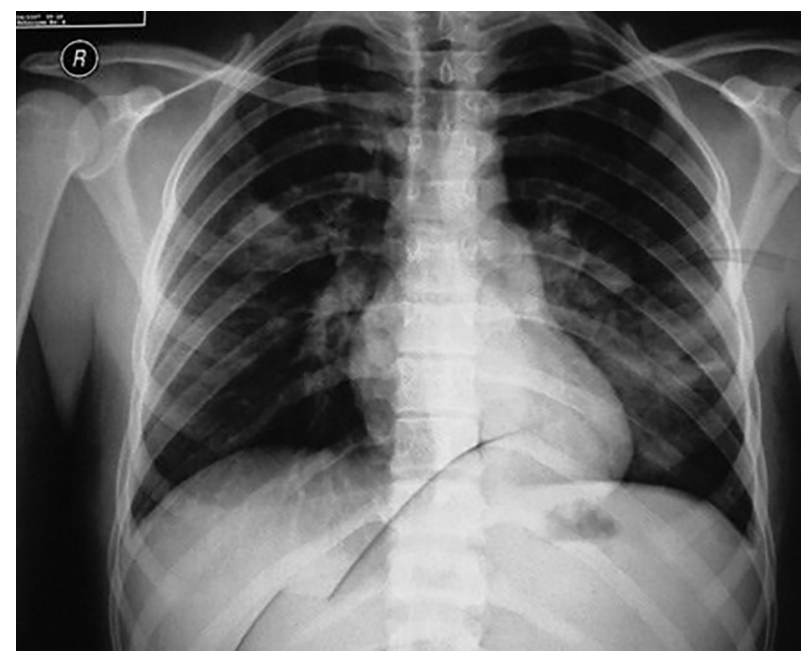

Figure 1. Chest X-ray illustrated diffuse bilateral patchy infiltration in case 1

\subsection{Case 2}

One week after hospitalization of the first patient, the other twin, a 14-month old boy, was hospitalized in the PICU due to respiratory distress. After hospitalization, he was febrile with restlessness, tachypnea, and intercostal retraction. On physical examination, the patient had bilateral wheezing and mild crackle (Table 1). Other examinations were normal. A chest x-ray indicated bilateral lung inflation (Figure 2). The results of CBC test were as follows: hemoglobin: $12.6 \mathrm{mg} / \mathrm{dL}$, platelet: $298000 / \mu \mathrm{L}$, white blood cells: $6200 / \mu \mathrm{L}$ (neutrophil: $35 \%$, lymphocyte: $60 \%$, eosinophil: $2 \%$, monocyte: $3 \%$ ), hematocrit: $38.9 \%$, and red blood cells: $4800 / \mu \mathrm{L}$. Serum electrolytes were within normal ranges. PCR was done on a nasopharyngeal sample for investigation of influenza, due to the local outbreak and was negative. Also, the result of blood culture was negative for common bacterial microorganisms. Based on the multiplex PCR results on NPA of his sister, this test was performed for his NPA. The result was positive only for $\mathrm{HBoV}$ 
infection. Salbutamol and ceftriaxone were prescribed. Also, essential care was done for the patient. Antibiotic was stopped gradually as the patient's general condition got better. Finally, after 6 days of hospitalization, he was discharged with a good general condition.

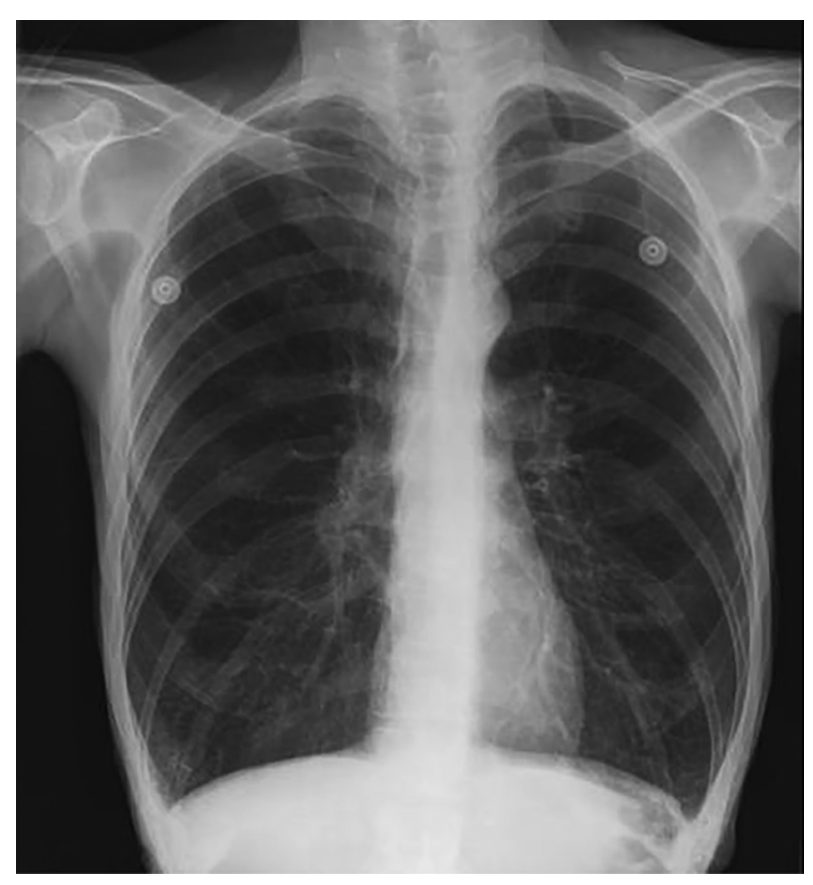

Figure 2. Chest X-ray illustrated diffuse bilateral patchy infiltration in case 2

\section{Discussion}

It is well known that respiratory infections are the most important cause of death among children below the age of five, and most of the respiratory infections are viral $(11,12)$. HBoV is one of the prevalent causes in children under two years of age, and its clinical manifestations range from mild respiratory symptoms to pneumonia (13). Coinfections with $\mathrm{HBoV}$ is common, and especially, bacterial co-infections can cause severe pneumonia as observed in our patient (9,14-16).

$\mathrm{HBoV}$ has been reported as the most common cause of infection and, after major viral respiratory pathogens, can result in ARI in children younger than three years old (17, 18). For example, a report by Calvo et al. on single infections and dual infections of $\mathrm{HBoV}$, in which $\mathrm{HBoV}$ was detected in $9.9 \%$ of the cases as a distinctive pathogen and in $75 \%$ of cases, as co-infections with other viral agents (19, 20) and also a report by Mohammadi et al. (9). There is no definitive report of $\mathrm{HBoV}$ co-infection with S. pneumoniae, and this report is a novel view of $\mathrm{HBoV}$ co-infection form.
Symptoms of HBoV respiratory infection cannot be differentiated from other respiratory infections. Also, the virus can be detected from respiratory secretions of asymptomatic patients. Most of the published articles and case reports used molecular methods for the detection of $\mathrm{HBoV}$ in nasopharyngeal samples, as we did by multiplex PCR (14, $16,21)$. Rapid molecular diagnostic tests help clinicians to make an accurate and quick diagnosis and techniques like multiplex PCR can detect numerous pathogens depicted in a single specimen so, it is advantageous for precise diagnosis of multi-organism infections (16).

Foulongne et al. studied 589 children under five years of age with ARI that $4.4 \%$ of their nasopharyngeal aspirates were positive for $\mathrm{HBoV}$, and $34.6 \%$ of these patients were coinfected with other viral pathogens. Bronchiolitis was the most probable diagnosis of these patients, and their common symptoms were dyspnea, respiratory distress, cough, and fever (21). Also, our patients had a fever and respiratory distress, and the diagnosis of bronchiolitis was made. The case reported by Ursic et al. discussed the clinical picture of a 20-month-old girl who was born prematurely at 27 weeks of gestation. The patient presented with respiratory distress and other signs of ARI and was diagnosed with bronchiolitis. In further assessments, HBoV was detected as the culprit by molecular methods (22). Also, Etemadi et al. reported a 13-month-old boy who was born prematurely at 33 weeks of gestation. The patient had a history of the previous hospitalization due to respiratory disease and presented with fever, cough, and respiratory distress. Finally, HBoV infection was confirmed by molecular diagnostic tests (23). In both case reports and in our case, patients were born prematurely, and also, the history of previous respiratory illness was positive in our case and the case report by Ursic et al. Therefore, these two factors can be mentioned as predisposing factors for $\mathrm{HBOV}$ infection.

Mohammadi et al. indicated a co-infection of $\mathrm{HBoV}$ and respiratory syncytial virus found in 44 (65.6\%) of $500 \mathrm{HBoV}$ positive samples (9). However, in our report, we indicated all major viral agents and also bacterial agents in pneumoniae. We confirmed that $\mathrm{HBoV}$ can be a major pathogen and life-threatening status in neonates in mono-infection form, and it is a major issue in pediatric infection.

In our report, the first case of respiratory failure was associated with lung infection by $\mathrm{HBoV}$ and S. pneumoniae co-infection, and finally, the patient was discharged. Although the second case was also positive for bocavirus infection, the patient's clinical condition improved after treatment.

\subsection{Conclusion}

It is known that $\mathrm{HBoV}$ can be associated with a wide range of respiratory symptoms, especially in premature 
neonates, and can be a life-threatening status in neonatal patients in mono-infection form; however, further studies are necessary to clarify its pathogenicity in lower respiratory tract infections.

\section{Footnotes}

Conflict of Interests: The authors declare that there is no conflict of interest regarding the publication of this article.

Ethical Approval: This study was approved by two ethical committees: Shahid Beheshti University of Medical Sciences, Tehran, IR Iran, Pediatric Infections Research Center, Mofid Children's Hospital, Shahid Beheshti University of Medical Sciences, Tehran, IR Iran. Adult subjects or parents of the child subjects signed the consent form for participation in the study. All procedures conducted in human studies were in accordance with the ethical standards of the Pediatric Infections Research Center (PIRC) Research Committee and the 1964 Helsinki Declaration and its later amendments or comparable ethical standards.

Funding/Support: The authors did not receive any funding for performing this research.

Informed Consent: The informed consed was obtained from patient.

\section{References}

1. Kelly MS, Sandora TJ. Community-Acquired Pneumonia. In: Kliegman RM, editor. Nelson Textbook of Pediatrics. 2. Philadelphia: Elsevier;2020.

2. Ziyade N, Sirin G, Elgormus N, Das T. Detection of Human Bocavirus DNA by Multiplex PCR Analysis: Postmortem Case Report. Balkan Med J. 2015;32(2):226-9. doi: 10.5152/balkanmedj.2015.15254. [PubMed: 26167351]. [PubMed Central: PMC4432707].

3. Allander T, Tammi MT, Eriksson M, Bjerkner A, Tiveljung-Lindell A, Andersson B. Cloning of a human parvovirus by molecular screening of respiratory tract samples. Proc Natl Acad Sci U S A. 2005;102(36):128916. doi: 10.1073/pnas.0504666102. [PubMed: 16118271]. [PubMed Central: PMC1200281].

4. Silva PE, Figueiredo CA, Luchs A, de Paiva TM, Pinho MAB, Paulino RS, et al. Human bocavirus in hospitalized children under 5 years with acute respiratory infection, Sao Paulo, Brazil, 2010. Arch Virol. 2018;163(5):1325-30. doi: 10.1007/s00705-017-3694-5. [PubMed: 29392492]. [PubMed Central: PMC7087275].

5. Moesker FM, van Kampen JJ, van der Eijk AA, van Rossum AM, de Hoog M, Schutten M, et al. Human bocavirus infection as a cause of severe acute respiratory tract infection in children. Clin Microbiol Infect. 2015;21(10):964 e1-8. doi: 10.1016/j.cmi.2015.06.014. [PubMed: 26100374]. [PubMed Central: PMC7172568].

6. Mohammadi M, Sabzi N, Bahrami N, Fathizadeh H. An Association Between HBoV and Acute Gastroenteritis in a 2-Month-Old Infant: A Case Report. Thrita. 2020;8(2). e99588. doi: 10.5812/thrita.99588.

7. Jartti T, Hedman K, Jartti L, Ruuskanen O, Allander T, SoderlundVenermo M. Human bocavirus-the first 5 years. Rev Med Virol. 2012;22(1):46-64. doi: 10.1002/rmv.720. [PubMed: 22038931].

8. Dina J, Vabret A, Gouarin S, Petitjean J, Lecoq J, Brouard J, et al. Detection of human bocavirus in hospitalised children.J Paediatr
Child Health. 2009;45(3):149-53. doi: 10.1111/j.1440-1754.2008.01442.x. [PubMed: 19210599]. [PubMed Central: PMC7167115].

9. Mohammadi M, Armin S, Yazdanpour Z. Human bocavirus infections and co-infections with respiratory syncytial virus and Rotavirus in children with acute respiratory or gastrointestinal disease. Braz J Microbiol. 2020;51(1):45-51. doi: 10.1007/s42770-019-00150-x. [PubMed: 31522356]. [PubMed Central: PMC7058740].

10. Gaviria Agudelo CL, Howard M, Barr MM, West M, Whitfield PL, Edwards J, et al. 2622. Multiplex Polymerase Chain Reaction (PCR) Panels in Pediatric Hospital Care: New Insights into Factors Driving Antimicrobial Use. Open Forum Infectious Diseases. 2019;6(Supplement_2):S913-4. doi:10.1093/ofid/ofz360.2300.

11. Everard ML. Paediatric respiratory infections. Eur Respir Rev. 2016;25(139):36-40. doi: 10.1183/16000617.0084-2015. [PubMed: 26929419].

12. Boloursaz MR, Lotfian F, Aghahosseini F, Cheraghvandi A, Khalilzadeh S, Farjah A, et al. Epidemiology of Lower Respiratory Tract Infections in Children. J Compr Ped. 2013;4(2):93-8. doi: 10.17795/compreped10273.

13. Mohammadi M, Yavarian J, Karbasizade V, Moghim S, Esfahani BN, Hosseini NS. Phylogenetic analysis of human bocavirus in children with acute respiratory infections in Iran. Acta Microbiol Immunol Hung. 2019;66(4):485-97. doi: 10.1556/030.66.2019.017. [PubMed: 31146533].

14. Liu WK, Liu Q, Chen DH, Tan WP, Cai Y, Qiu SY, et al. Epidemiology of HBoV1 infection and relationship with meteorological conditions in hospitalized pediatric patients with acute respiratory illness: a 7-year study in a subtropical region. BMC Infect Dis. 2018;18(1):329. doi: 10.1186/s12879-018-3225-3. [PubMed: 30012099]. [PubMed Central: PMC6048719].

15. Meriluoto M, Hedman L, Tanner L, Simell V, Makinen M, Simell S, et al. Correction: Vol. 18, No. 2. Emerg Infect Dis. 2016;22(9):1695. doi: 10.3201/eid2209.C12209. [PubMed: 27390872]. [PubMed Central: PMC4994360].

16. Peltola V, Soderlund-Venermo M, Jartti T. Human bocavirus infections. Pediatr Infect Dis J. 2013;32(2):178-9. doi: 10.1097/INF.0b013e31827fef67. [PubMed: 23328822].

17. Kim S, Lee HN, Koo HJ, Choi SH, Sung H, Do K-H. Human Bocavirus Infection in Adults: Pneumonia risk factors and Radiologic Findings. European Congress of Radiology-ECR; 2019.

18. Christensen A, Kesti O, Elenius V, Eskola AL, Døllner H, Altunbulakli C et al. Human bocaviruses and paediatric infections. The Lancet Child $\mathcal{E}$ Adolescent Health. 2019;3(6):418-26. doi: 10.1016/s2352-4642(19)300574.

19. Calvo C, Garcia-Garcia ML, Pozo F, Carballo D, Martinez-Monteserin E, Casas I. Infections and coinfections by respiratory human bocavirus during eight seasons in hospitalized children. $J$ Med Virol. 2016;88(12):2052-8. doi: 10.1002/jmv.24562. [PubMed: 27124519]. [PubMed Central: PMC7166349].

20. Calvo C, Garcia-Garcia ML, Pozo F, Paula G, Molinero M, Calderon A, et al. Respiratory Syncytial Virus Coinfections With Rhinovirus and Human Bocavirus in Hospitalized Children. Medicine (Baltimore). 2015;94(42). e1788. doi: 10.1097/MD.0000000000001788. [PubMed: 26496310]. [PubMed Central: PMC4620789].

21. Foulongne V, Olejnik Y, Perez V, Elaerts S, Rodiere M, Segondy M. Human bocavirus in French children. Emerg Infect Dis. 2006;12(8):12513. doi: 10.3201/eid1708.060213. [PubMed: 16965707]. [PubMed Central: PMC3291226].

22. Ursic T, Steyer A, Kopriva S, Kalan G, Krivec U, Petrovec M. Human bocavirus as the cause of a life-threatening infection. J Clin Microbiol. 2011;49(3):1179-81. doi: 10.1128/JCM.02362-10. [PubMed: 21227992]. [PubMed Central: PMC3067724].

23. Etemadi MR, Azizi Jalilian F, Abd Wahab N, Jahanshiri F, Amini R, Othman N, et al. First detected human bocavirus in a Malaysian child with pneumonia and pre-existing asthma: a case report. Medical Journal of Malaysia. 2012;67(4):433-4. 